\title{
Reduced Swimming Performance Repeatedly Evolves on Loss of Migration in Landlocked Populations of Alewife
}

\author{
Jonathan P. Velotta ${ }^{1, *}$ \\ Stephen D. McCormick ${ }^{2}$ \\ Andrew W. Jones ${ }^{3}$ \\ Eric T. Schultz ${ }^{1}$ \\ ${ }^{1}$ University of Connecticut, Department of Ecology and \\ Evolutionary Biology, Storrs, Connecticut 06269 \\ ${ }^{2}$ US Geological Survey, Leetown Science Center, Conte \\ Anadromous Fish Research Laboratory, Turners Falls, \\ Massachusetts 01376; ${ }^{3}$ Woods Hole Oceanographic Institute, \\ Woods Hole, Massachusetts 02543
}

Accepted 11/20/2017; Electronically Published 1/30/2018

\begin{abstract}
Whole-organism performance tasks are accomplished by the integration of morphological traits and physiological functions. Understanding how evolutionary change in morphology and physiology influences whole-organism performance will yield insight into the factors that shape its own evolution. We demonstrate that nonmigratory populations of alewife (Alosa pseudoharengus) have evolved reduced swimming performance in parallel, compared with their migratory ancestor. In contrast to theoretically and empirically based predictions, poor swimming among nonmigratory populations is unrelated to the evolution of osmoregulation and occurs despite the fact that nonmigratory alewives have a more fusiform (torpedo-like) body shape than their ancestor. Our results suggest that elimination of longdistance migration from the life cycle has shaped performance more than changes in body shape and physiological regulatory capacity.
\end{abstract}

\section{Introduction}

Whole-organism performance- the ability to conduct an ecologically relevant task (Lailvaux and Irschick 2006; Irschick

\footnotetext{
${ }^{*}$ Corresponding author. Present address: University of Montana, Division of Biological Sciences, Missoula, Montana 59812; e-mail: jonathan.velotta@ gmail.com
}

Physiological and Biochemical Zoology 91(2): 814-825. 2018. (C) 2018 by The University of Chicago. All rights reserved. 1522-2152/2018/9102-7020\$15.00. DOI: $10.1086 / 696877$ et al. 2008) - is accomplished by the integration of both morphological and physiological components (Arnold 1983; Bennett and Huey 1990; Garland and Losos 1994; Irschick and Garland 2001; Irschick 2003; Irschick et al. 2008). Although it is thus clear that adaptive changes in performance are potentially shaped by natural selection on an array of morphological and physiological traits, assessing how performance evolves has been challenging because ancestral phenotypes and agents of selection are usually not known. We describe the evolution of locomotor performance in an ancestrally migratory fish that has recently and repeatedly formed nonmigratory populations. Our empirical approach was based on a priori predictions about how swimming performance would be shaped by evolutionary changes in life-history strategy, morphology, and physiology. Such integrative investigations illuminate the complex relationship between changing environments and phenotypic evolution (e.g., Langerhans et al. 2007).

For many animal species, locomotor performance is an important aspect of fitness-related behaviors, such as foraging, escape, and migration (Garland et al. 2017). For migrating fishes in particular, prolonged swimming performance should be under directional selection in the wild. Conversely, fishes that exhibit little or no migratory behavior have relatively low prolonged swimming performance (e.g., Dalziel et al. 2012b). In sockeye salmon (Oncorhynchus nerka), for example, maximum metabolic rate and prolonged swimming performance are higher in populations that make long-distance migrations than in populations that make exclusively short-distance migrations (Lee et al. 2003; Eliason et al. 2011, 2013).

In addition to migratory demands, locomotion can evolve in concert with changes in body morphology that accompany changes in habitat. High-predation environments, for example, may favor burst swimming abilities over prolonged, steadyswimming abilities (Langerhans and Reznick 2010). Such evolved differences in burst and prolonged swimming performance have well-documented biophysical dependencies on body and fin shape (Webb 1982; Walker 1997; Domenici et al. 2008; Langerhans and Reznick 2010; Dalziel et al. 2012b). Specifically, theory and empirical work suggest that fusiform shapes enhance prolonged swimming performance over more other body forms (Webb 1982, 1984; Walker 1997; Langerhans and Reznick 2010; Ellerby and Gerry 2011). This divergence in shape is commonly associated with differences in habitat usage, such that robust body shapes enhance maneuverability beneficial to complex habitats, whereas fusiform shapes enhance the prolonged swimming abilities beneficial in the open water (e.g., Jones et al. 2013).

Evolutionary changes in physiological abilities should also affect swimming performance. For example, maximum sustained swimming speed is positively correlated with maximum and stan- 
dard metabolic rates as well as the capacity of the cardiorespiratory system to deliver oxygen and fuel to tissues (Claireaux et al. 2005; Eliason et al. 2011, 2013; Dalziel et al. 2012a, 2012b; Eliason and Farrell 2016; Norin and Clark 2016). For euryhaline fishes in particular, osmoregulatory physiology may influence swimming performance, although this has been less well characterized. Transfer from freshwater to saltwater or vice versa reduces prolonged swimming performance in several species (Kolok and Sharkey 1997; Swanson 1998; Plaut 2000; McKenzie et al. 2001; Wagner et al. 2006) for several possible reasons that are not mutually exclusive: (1) because changes in ion concentration reduce muscle oxygen delivery (Brauner et al. 1994), (2) because of the energetic expense associated with osmoregulation (Tseng and Hwang 2008), or (3) because ionocyte proliferation and/or decreased lamellar perfusion associated with changes in osmoregulation limit the efficiency of gas exchange and thus maximum metabolic rate (Bindon et al. 1994; Sardella and Brauner 2007). Such negative associations between osmoregulatory abilities and performance may act to shape evolutionary trade-offs in nature. For example, estuarine populations of Fundulus heteroclitus have higher critical swimming speeds in brackish water than natives of upstream freshwater habitats (Brennan et al. 2016). Because estuarine F. heteroclitus maintain ion balance more effectively after transfer to brackish water (Brennan et al. 2015), natural selection on osmoregulatory phenotypes may indirectly select on swimming performance.

We tested how evolutionary changes in multiple and potentially interacting traits have influenced swimming performance in alewife (Alosa pseudoharengus) from the northeastern United States. This opportunity arises because exclusively freshwater (landlocked) populations have repeatedly and independently formed from an anadromous ancestor, most likely as the result of widespread dam building during European colonial settlement (though exact dates of formation are unknown; Palkovacs et al. 2008). Population genetic analyses using microsatellite loci indicate that landlocked populations in Connecticut are independently derived from a common ancestral anadromous stock (Palkovacs et al. 2008). Unlike anadromous alewife that make long-distance journeys from the sea to coastal lakes and streams (Fay et al. 1982), landlocked alewife no longer migrate. We have shown previously that landlocked alewife have diverged from anadromous alewife in osmoregulatory ability, including a reduction in saltwater tolerance and hypo-osmotic balance that corresponds with an improved tolerance of freshwater (Velotta et al. 2015). Previous work has also demonstrated that alewife populations differ in body shape, most likely as a result of differentiation in nursery habitat foraging; whereas landlocked forms feed in the pelagic zone, anadromous alewife feed in the littoral (Jones et al. 2013). Divergence in feeding strategy has putatively selected for more fusiform shapes and narrower caudal peduncles in landlocked forms, which are hypothesized to perform more prolonged bouts of steady swimming in order to feed in the pelagic zone (as postulated in Jones et al. 2013). By contrast, anadromous alewife are robust in body shape and have larger heads (Jones et al. 2013), which is consistent with their preference for feeding in more complex littoral habitat.
We subjected alewife from an anadromous population and two independently derived landlocked populations to $24-\mathrm{h}$ freshwater and saltwater treatments, followed by assays of prolonged swimming performance (measured as critical swimming speed [ $\left.U_{\text {crit }}\right]$; Brett 1964; Beamish 1978; Hoar and Randall 1978; Farrell 2007), osmoregulatory abilities, and body shape. Critical swimming speed - the ability to maintain a constant swimming speed (Hoar and Randall 1978) - is an ecologically relevant measure of prolonged swimming performance in migratory species (Jain et al. 1998; Kolok 1999; Plaut 2001; Lee et al. 2003). We measured plasma osmolality after critical swimming speed trials in order to assess whether variation in $U_{\text {crit }}$ is associated with postexercise deviations in osmotic balance. We analyzed variation in body shape using geometric morphometrics (Adams et al. 2004; Zelditch et al. 2012) and related it to variation in $U_{\text {crit }}$.

We tested three alternative hypotheses of the ultimate factors affecting swimming performance. Hypothesis 1: Prolonged swimming performance is constrained by osmoregulatory performance. This hypothesis predicts that $U_{\text {crit }}$ varies with the capacity to maintain osmotic homeostasis; $U_{\text {crit }}$ should be equal or greater among landlocked individuals in freshwater but reduced in seawater. Hypothesis 2: Prolonged swimming performance evolves in conjunction with body morphology. This hypothesis predicts that more fusiform landlocked fish should have higher $U_{\text {crit }}$ than anadromous fish. Hypothesis 3: Prolonged swimming performance evolves in concert with migratory tendency. This hypothesis predicts that landlocked individuals should exhibit a reduced $U_{\text {crit }}$ as a result of the loss of traits associated with migration. We found that landlocked alewife have poor prolonged swimming performance in spite of their more fusiform body shape and regardless of osmoregulatory state. Our results support the hypothesis that loss of the anadromous migration from the life cycle leads to a loss of locomotor performance, likely as a result of natural selection on aerobic metabolism and cardiac function.

\section{Methods}

\section{Capture and Husbandry}

Young-of-the-year alewife (approximately 3-4 mo old) were captured by purse seine from their natal freshwater lakes in Connecticut in August 2013 and were immediately transported to the Conte Anadromous Fish Research Center in Turners Falls, Massachusetts. All animals were handled in accordance with the University of Connecticut Institute for Animal Care and Use Committee (protocol A12-042). We captured individuals from three populations: an anadromous population from Bride Lake (ABride; East Lyme, CT; $\left.41.33^{\circ} \mathrm{N}, 72.24^{\circ} \mathrm{W}\right)$ and landlocked populations from Pattagansett Lake (L-Pattagansett; East Lyme, $\mathrm{CT} ; 43.47^{\circ} \mathrm{N}, 72.23^{\circ} \mathrm{W}$ ) and Rogers Lake (L-Rogers; Old Lyme, $\left.\mathrm{CT} ; 41.37^{\circ} \mathrm{N}, 72.30^{\circ} \mathrm{W}\right)$; sites differed little in salinity and conductivity (Velotta et al. 2015). Approximately 150 individuals were collected from each site. Young-of-year alewife collected at this time have had no prior exposure to seawater and no prior experience migrating. Fish were transported in aerated 190-L cylindrical containers containing lake water into which artificial 
sea salt was dissolved to 1 ppt (Instant Ocean, Spectrum Brands, Madison, WI) to reduce stress and mortality associated with handling (Stanley and Colby 1971; Johnson and Metcalf 1982; Nikinmaa et al. 1983; Carneiro and Urbinati 2001). Once in the laboratory, alewives were held at $1 \mathrm{ppt}$ for $1 \mathrm{~d}$, after which salinity was decreased to $0.5 \mathrm{ppt}$ (final rearing salinity). We held subjects segregated by population in separate 1,200 -L recirculating oval tanks fitted with charcoal filtration systems for 2 mo before swimming performance trials. Such a period of acclimation to a common environment is standard practice (e.g., Whitehead and Crawford 2006; Whitehead et al. 2011; Brennan et al. 2015; Velotta et al. 2015) to minimize potential confounding effects of environmental history in resolving among-population genotypic effects on the phenotypes of interest.

\section{Salinity Challenge and Swimming Speed Trials}

To test whether divergence in osmoregulatory ability influences swimming performance, we exposed fish to acute $(24 \mathrm{~h})$ treatments of fresh- and saltwater followed by swimming trials to measure $U_{\text {crit }}$. Treatments and trials lasted from OctoberNovember 2013. Acute challenge via direct transfer to a treatment salinity is a standard method to assess the osmoregulatory performance of fishes and allows for comparison across studies of alewife (Velotta et al. 2014,2015) and other euryhaline fishes (reviewed in Schultz and McCormick 2013; see also Whitehead 2010; Whitehead et al. 2011, 2012; Berdan and Fuller 2012; McCormick 2013; Kozak et al. 2014; Brennan et al. 2015). We chose the method of direct transfer rather than gradual salinity change because it is ecologically relevant: out-migrating youngof-year individuals from Bride Lake pass from a small freshwater stream (approximately 5 -m bankfull width) directly into the Long Island Sound, with no marsh-like area in between or opportunity for backflow of saltwater into freshwater (J. P. Velotta, S. D. McCormick, A. W. Jones, and E. T. Schultz, personal observation). A treatment of $24 \mathrm{~h}$ is sufficient for measurement of responses in gene expression and cellular change and roughly represents the time when physiological stresses are greatest, as quantified by changes in plasma osmolality and mortality rate (Staurnes et al. 1992; Zydlewski and McCormick 1997; Scott and Schulte 2005; Whitehead et al. 2011; Velotta et al. 2014, 2015).

For salinity challenge treatments, we transferred seven to 10 fish from rearing tanks $(0.5 \mathrm{ppt})$ directly to aerated $250-\mathrm{L}$ oval tanks containing either 0 ppt freshwater, a 0.5 ppt control, or saltwater at 35 or $40 \mathrm{ppt}$. Control and saltwater treatments were achieved by mixing dechlorinated tap water with artificial sea salt (Crystal Sea Marine Mix, Marine Enterprises International, Baltimore, MD), while the freshwater treatment (0 ppt) consisted of dechlorinated tap water only. Tank temperature was maintained at $17^{\circ}-19^{\circ} \mathrm{C}$ with electric tank heaters. Salinity treatments used in this study span and exceed values found in the species' habitat. Conductivity in the freshwater treatment $(\sim 250 \mu \mathrm{S})$ approximated the conductivity of alewife juvenile habitat (Velotta et al. 2015). Similarly, the saltwater treatment was chosen to represent natural (35 ppt) conditions, while
40 ppt was chosen to test the limits of hypo-osmoregulation (Velotta et al. 2015; Divino et al. 2016).

Swimming trials occurred $24 \mathrm{~h}$ after the salinity challenge treatment. Each day of swimming trials tested up to three subjects, all from a single combination of population and salinity. Each combination of population and salinity was tested until $n=5-6$ individuals were assayed. To measure $U_{\text {crit }}$, we swam fish individually in a 5-L Brett style swim tunnel (Loligo Systems, Hobro), in which flow speed was increased incrementally as described below. We matched the temperature $\left(17^{\circ}-19^{\circ} \mathrm{C}\right)$ and salinity of the water in the swim tunnel to that of the salinity challenge tank. Subjects acclimated to the swim tunnel for $1 \mathrm{~h}$ at 0.5 total body lengths per second ( $\mathrm{TL} \mathrm{s} \mathrm{s}^{-1}$ ). We then increased flow speed by $0.5 \mathrm{TL} \mathrm{s}^{-1}$ every $2 \mathrm{~min}$ until the fish reached $5 \mathrm{TL} \mathrm{s}^{-1}$, which is $50 \%$ of a predicted average $U_{\text {crit }}\left(10 \mathrm{TL} \mathrm{s}^{-1}\right)$ observed in a pilot study. Above $5 \mathrm{TL} \mathrm{s}^{-1}$, flow speed was increased by $0.5 \mathrm{TL} \mathrm{s}^{-1}$ every 10 min until the fish remained pinned against the downstream barrier of the tunnel for $>10 \mathrm{~s}$. In the pilot study, fish pinned for longer than $10 \mathrm{~s}$ did not resume swimming. Each fish occupied less than $15 \%$ of the cross-sectional area of the tunnel, and therefore a correction for solid blocking effects was not needed.

We determined critical swimming speed $\left(\mathrm{TL} \mathrm{s}^{-1}\right)$ as described by Brett (1964):

$$
U_{\text {crit }}=U_{\mathrm{i}}+\left(\frac{t_{\mathrm{i}}}{t_{\mathrm{ii}}} U_{\mathrm{ii}}\right),
$$

where $U_{\mathrm{i}}$ is the highest speed the fish is able to swim for a full 10 -min interval; $U_{\text {ii }}$ is 0.5 , the increment at which speed is increased; $t_{\mathrm{i}}$ is the time in minutes that the fish swam at the final velocity; and $t_{\mathrm{ii}}$ is 10 , the time fish swam at each interval. To set the speed increments we used for each subject, we estimated TL before placement into the swim tunnel from an image taken in water. In cases where the length estimated before the trial differed from the length determined after the subject was euthanized, we adjusted $U_{\mathrm{i}}$ by dividing the velocity at failure $\left(\mathrm{cm} \mathrm{s}^{-1}\right)$ by the actual TL.

Differences in $U_{\text {crit }}$ among alewife life-history forms and salinity treatments were tested using linear mixed effects models (LMMs) generated using the lmer function in R (lme4 package; $\mathrm{R}$ ver. 3.1.0). Full models included population (A-Bride, $\mathrm{L}-$ Pattagansett, or L-Rogers) and salinity (0, 0.5 [control], 35, and $40 \mathrm{ppt}$ ) as fixed effects, TL as a covariate, and swimming trial as a random effect. $P$ values were calculated with the anova function in the LmerTest package ( $\mathrm{R}$ ver. 3.1.0) using restricted maximum likelihood and Satterthwaite estimation for denominator degrees of freedom. We implemented a model reduction approach, whereby nonsignificant $(P>0.05)$ interaction terms were eliminated sequentially. Tukey honest significant difference post hoc tests (multcomp package in $\mathrm{R}$ ) were used to determine pairwise differences among populations and salinity treatments.

\section{Analysis of Body Shape and Plasma Osmolality}

After each swimming trial, we euthanized fish in $250 \mathrm{mg} \mathrm{L}^{-1}$ tricaine methanesulfonate (MS-222; Argent, Redmond, WA) and measured TL and body mass. We then straightened them with insect pins and photographed them from a standard dis- 
tance on a white background. We then severed the caudal fin and collected blood from the caudal artery in a 1-mL heparinized hematocrit tube. Blood was centrifuged at 3,200 $\mathrm{g}$ for $5 \mathrm{~min}$, after which plasma was removed and stored at $-80^{\circ} \mathrm{C}$. We measured plasma osmolality, the total plasma solute concentration, using a vapor pressure osmometer (Wescor, Logan, $\mathrm{UT}$ ) with approximately $8 \mu \mathrm{L}$ of plasma, following the manufacturer's instructions. Depending on the amount of available plasma, we ran samples in duplicate or triplicate and took the average reading as the final value of osmolality.

To quantify body shape variation, we used landmark-based geometric morphometrics approach (Zelditch et al. 2012) following the procedure of Jones et al. (2013), who analyzed body shape of young-of-year in each of the populations presented here, as well as three additional landlocked and anadromous populations. We placed 11 landmarks (fig. 1) using tpsDig2 v2.16 (Rohlf 2010) on approximately 20 individuals from each of the three populations. We then used the Procrustes fit function in MorphoJ v1.02 (Klingenberg 2011) to generate the consensus shape (Rohlf and Slice 1990; Adams et al. 2004; Zelditch et al. 2012). To identify the predominant axes of variation in body shape, we conducted principal components analysis (PCA) on the covariance matrix of Procrustes coordinates. We then performed a discriminant function analysis (DFA) to describe the axis of body shape variation that best distinguishes the landlocked and anadromous life-history forms. We tested for statistical differences in PCA and DFA scores between populations using LMMs, in which population was a main effect, swimming trial was a random effect, and TL was a covariate. To determine whether body shape variation influences swimming performance, we correlated PCA scores from each of the first three principal components (PCs) with $U_{\text {crit }}$ using Pearson's correlation. Body shape variation in the PCA and DFA were visualized using wireframe graphs generated in MorpoJ at a scale factor of \pm 0.1 . We computed fineness ratio (standard length/body depth; as in Dalziel et al. 2015) as an additional metric of overall body shape that is related to steady swimming performance (Webb 1975; Fish 1996). Maximum body depth and standard length were obtained from images using Image (Schneider et al. 2012). Amongpopulation differences in fineness ratio were assessed via ANOVA.

We tested for population and salinity effects on postswim (after swimming performance trial) plasma osmolality $\left(\mathrm{mOsm} \mathrm{kg}^{-1}\right)$. LMMs were implemented as above. Full models tested for the main effects of population, salinity, and their interaction on osmolality. Fish TL was used a covariate. Random effects in each model included trial date and tank. $P$ values were calculated with the anova function in the LmerTest package as above. We tested for correlations between postswim plasma osmolality and $U_{\text {crit }}$ in order to determine whether differences in swimming performance are associated with deviations in osmoregulatory capacity at the individual level. We computed Spearman's rank correlation coefficients (cor.test function in R) since data did not meet the assumptions of normality. Under the hypothesis of a linkage between osmoregulatory abilities and swimming performance, the predicted direction of the correlation should be different in freshwater and saltwater; impaired osmoregulatory ability is indicated by low plasma osmolality in freshwater but high osmolality in saltwater. For this reason, we conducted correlation analysis separately within each salinity treatment.

\section{Results}

We found that prolonged swimming performance was significantly lower among landlocked alewife from both populations across all salinities. Anadromous alewife exhibited a $U_{\text {crit }}$ of 9.7 $\mathrm{TL} \mathrm{s}^{-1}$, which was 1.8 and $2.8 \mathrm{TL} \mathrm{s}^{-1}$ higher than individuals from L-Pattagansett and L-Rogers, respectively (fig. 2). Full LMMs contained no significant three-way or two-way interactions $(P>0.05)$, and so a reduced model included only main effects (population and salinity) and TL as a covariate. This

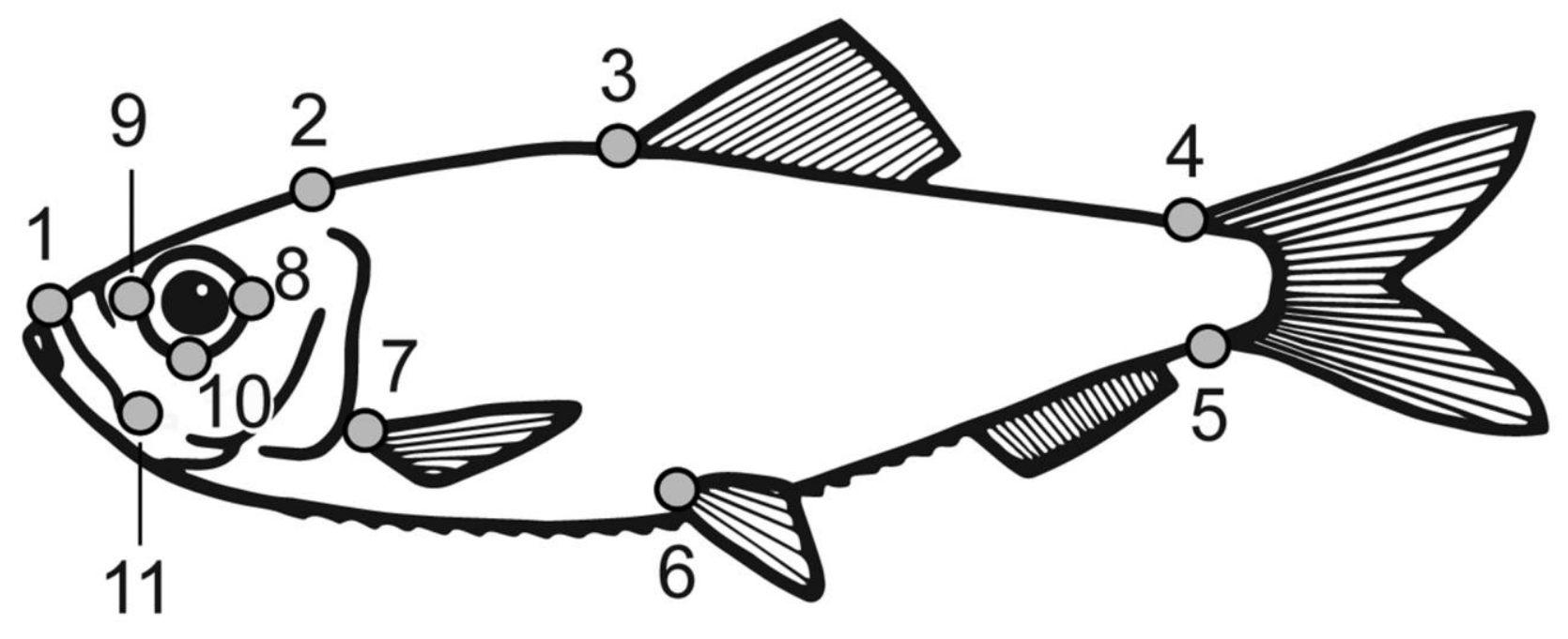

Figure 1. Location of the 11 landmarks used for geometric morphometric analysis of body shape. For further detail, see Jones et al. (2013). Image depicts a representative juvenile alewife. 


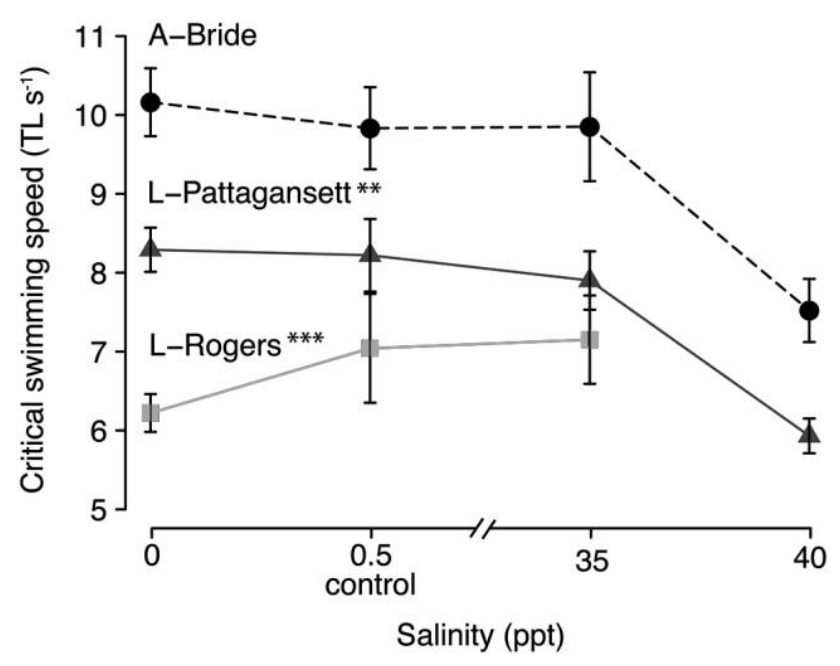

Figure 2. Critical swimming speed ( $U_{\text {crit }}$ total body lengths per second [TL s${ }^{-1}$ ) of landlocked (L-Pattagansett, triangles and solid line; LRogers, squares and solid line) and anadromous (A-Bride, circles and dashed line) alewives subjected to 24 -h challenge at $0,0.5$ (control), 35 , and 40 ppt $(n=4-6$ per salinity per population. Data are presented as mean $U_{\text {crit }} \pm$ SE error of the mean. Main effect of population relative to A-Bride: two asterisks, $P<0.01$; three asterisks, $P<0.001$. A color version of this figure is available online.

model revealed significant effects of population and salinity on $U_{\text {crit }}$ (table 1). Post hoc tests revealed that $U_{\text {crit }}$ differed between L-Pattagansett and A-Bride $(z=-3.7, P<0.001)$ and between L-Rogers and A-Bride $(z=-5.8, P<0.001)$ but not between the two landlocked populations $(z=-2.3, P>0.05)$. High salinity significantly impaired swimming; $U_{\text {crit }}$ was lower at $40 \mathrm{ppt}$ than at all other salinities (0.5 ppt: $z=-2.9, P=0.02$; 0 ppt: $z=-2.2, P=0.02 ; 35$ ppt: $z=-3.1, P=0.009)$. Elevated mortality prevented measurement of $U_{\text {crit }}$ in L-Rogers alewife at 40 ppt. Models in which $U_{\text {crit }}$ was expressed as absolute speed $\left(\mathrm{cm} \mathrm{s}^{-1}\right)$ yielded the same population and salinity effects.

Landlocked and anadromous alewife differed in body shape, primarily in head shape and caudal peduncle size (fig. 3). Three PCs explained variance in shape $(34.9 \%, 18.5 \%$, and $14.7 \%$, respectively). We observed significant differences among populations along PC2 $\left(F_{2,13.7}=4.5, P=0.03\right.$; nonsignificant effect of TL, $P>0.05$ ) but not PC1 or PC3. PC2 values of both landlocked populations were significantly different from those of A-Bride (L-Pattagansett: $z=2.7, P=0.020$; L-Rogers: $z=$ 2.5. $P=0.037)$. Loadings on $\mathrm{PC} 2$ indicated that populations differed in head and caudal peduncle size (fig. $3 A$; LMM of DFA scores $\left.F_{2,45}=89.1, P<0.001\right)$. Analysis of fineness ratio confirmed that landlocked alewife are more fusiform than anadromous alewife; ANOVA revealed a significant effect of population on fineness ratio $\left(F_{2,51}=5.99, P=0.005\right)$. Post hoc tests revealed that individuals from A-Bride have a significantly lower fineness ratio compared with individuals from LPattagansett $(P=0.006)$ and L-Rogers $(P=0.03)$ and that landlocked populations do not differ from each other $(P>0.05)$. Body shape was correlated with critical swimming speed (fig. $3 B$ ).
Across all populations, $U_{\text {crit }}$ was significantly and negatively correlated with PC2 scores, indicating that fish with more fusiform body shapes had lower critical swimming speeds than those with robust shapes. No correlations between $U_{\text {crit }}$ and PC1 or PC3 were detected $(P>0.05)$. $U_{\text {crit }}$ was negatively correlated with fineness ratio $(r=-0.26)$, but this trend was not statistically significant $(P=0.06)$.

Population and salinity affected plasma osmolality after acute salinity challenge and swimming trials. Plasma osmolality was lower at 0 and 0.5 ppt than at 35 and 40 ppt (fig. 4; effect of salinity: $\left.F_{3,14.6}=101.2, P<0.001\right)$ and was lower among anadromous compared with landlocked fish (effect of population: $\left.F_{2,13}=3.8, P=0.05\right)$. The effect of acute salinity challenge on plasma osmolality did not vary among populations (interaction: $P>0.05)$. Swimming performance was not correlated with postswim osmolality across salinities $(P>0.05$; fig. 5$)$.

\section{Discussion}

We tested whether divergence in osmoregulatory ability, body form, or loss of long-distance migration as part of the life cycle provides the best explanation for changes in prolonged swimming performance as landlocked (nonmigratory) alewife have differentiated from the anadromous ancestral form. Landlocked populations have evolved a lower maximum sustained swimming speed (fig. 2). This reduction is unaffected by salinity (fig. 2) and independent of osmoregulatory ability (fig. 5). Although lifehistory form divergence in body shape (fig. $3 A$ ) was associated with swimming performance, it varied in a direction opposite of biophysical predictions (Langerhans and Reznick 2010; fig. 3B). Our results demonstrate that body shape, osmoregulation, and prolonged swimming performance are diverging in an uncorrelated fashion, most likely as a result of different selection pressures. We conclude that loss of migration is the strongest contributor of evolved differences in whole-organism swimming performance, a difference that is likely to be mediated by variation in aerobic metabolism and cardiorespiratory performance.

We found that alewife life-history forms differ in body shape but not in a fashion that clearly explains differences in prolonged swimming performance. Compared with the anadromous form, landlocked alewife have smaller heads and more fusiform bodies, principally owing to a reduced caudal peduncle height (fig. $3 A$ ). The patterns of morphological differentia-

Table 1: Effect of population, salinity, and length on $U_{\text {crit }}$

\begin{tabular}{lccrr}
\hline & $\begin{array}{c}\text { Numerator } \\
\text { df }\end{array}$ & $\begin{array}{c}\text { Denominator } \\
\text { df }\end{array}$ & \multicolumn{1}{c}{$F$} & \multicolumn{1}{c}{$P$} \\
\hline Population & 2 & 13.4 & 17.7 & $<.001$ \\
Salinity & 3 & 14.7 & 3.7 & $\mathbf{. 0 3 7}$ \\
Length & 1 & 43.3 & .5 & .466 \\
\hline
\end{tabular}

Note. Data are results of a reduced linear mixed effects model. Population has three levels (A-Bride, L-Pattagansett, L-Rogers), and salinity has four levels $(0,0.5,35$, and $40 \mathrm{ppt})$. Length is total length $(\mathrm{cm})$. Denominator $\mathrm{df}$ was generated by the Satterthwaite approximation method. Values in bold denote statistical significance at the 0.05 level. 


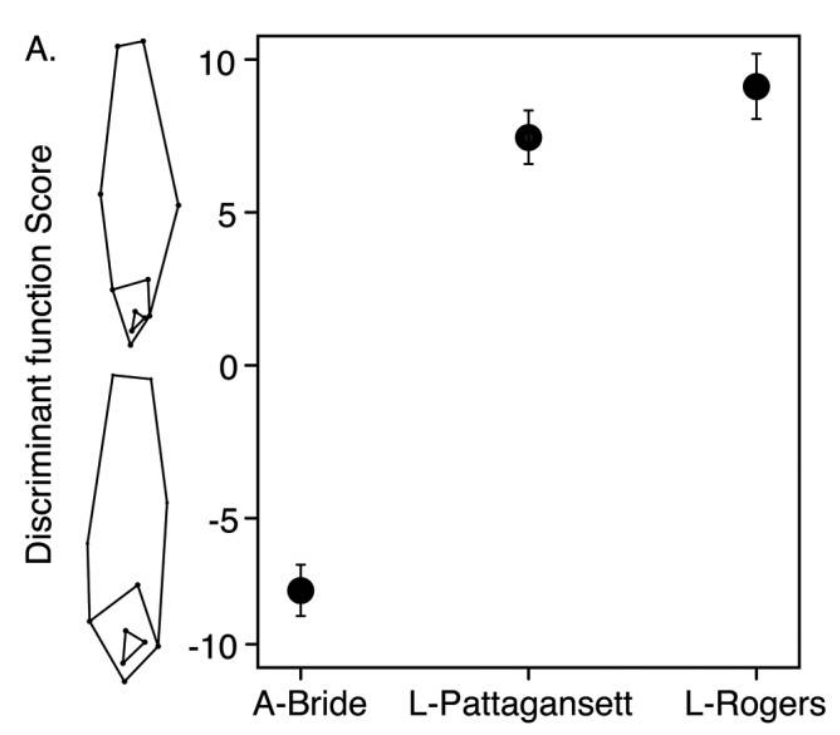

tat and abundant epibionts favor maneuverability and the ability to consume large prey. In contrast, landlocked fish feed mostly in the pelagic zone, where structural simplicity and abundant zooplankton may favor the ability to swim steadily and consume small prey. Our results do not speak to the feeding performance predictions of Jones et al. (2013). Our results do, however, contradict the swimming performance predictions: despite the body form differences, anadromous alewives exhibit higher $U_{\text {crit }}$ than landlocked alewives (fig. 2), suggesting that prolonged swimming performance has evolved in ways that depart from the generally understood association with body shape. In the future, it will be informative to test for life-history form differences in caudal fin shape, since, along with fusiform bodies, high caudal fin aspect ratios (height ${ }^{2}$ surface area $^{-1}$ ) should improve prolonged swimming performance by maximizing thrust and minimizing drag (reviewed in Langerhans and Reznick 2010).

We also found that life-history form differences in osmoregulatory abilities do not account for the differences in prolonged swimming performance. We observed lower $U_{\text {crit }}$ among landlocked alewife across all salinity treatments (fig. 2), despite comparable values of postswim osmolality (fig. 4). $U_{\text {crit }}$ was also uncorrelated with postswim osmolality at the individual level (fig. 5).

Similarity of plasma osmolality postswim between lifehistory forms is in striking contrast to previous measurements on unexercised fish that showed higher osmolality in landlocked alewife than anadromous alewife in seawater (Velotta et al. 2014, 2015). We did not measure plasma osmolality before swimming trails (preswim) because subjects are euthanized

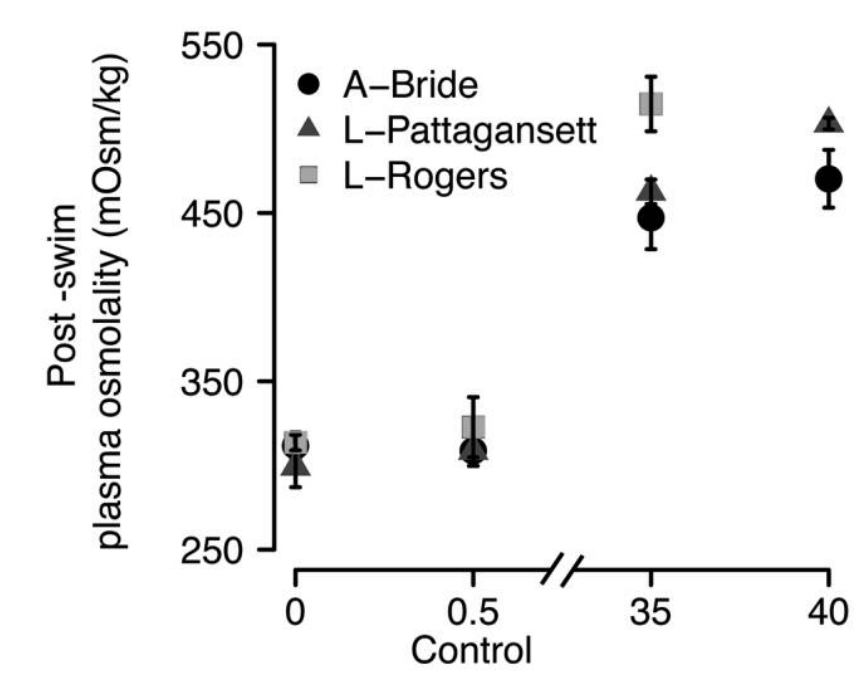

Salinity (ppt)

Figure 3. Morphological divergence and its effect on critical swimming speed $\left(U_{\text {crit }}\right)$. $A$, Body shape divergence between anadromous (A-Bride) and landlocked (L-Pattagansett and L-Rogers) alewives. Values are mean discriminant function analysis (DFA) scores for each population, which describe the axis of variation that best distinguished anadromous and landlocked body forms. Error bars represent 95\% confidence intervals. Figures along the $Y$-axis represent extreme cases of shape variation according to the DFA. B, Correlation between $U_{\text {crit }}$ (total body lengths per second $\left[\mathrm{TL} \mathrm{s}^{-1}\right]$ ) and body shape as described by the second principal components axis (PC2). PC2 scores described general body shape, head size, and caudal peduncle size. Figures under the $X$-axis represent extreme cases of shape variation along PC2. Shapes denote populations (circles, A-Bride; triangles, L-Pattagansett; squares, L-Rogers). A color version of this figure is available online.

tion were consistently observed in all lakes tested by Jones et al. (2013), who suggested that the ultimate causes of this divergence arise from differences in habitat use. Anadromous young-of-year alewives feed in the littoral zone, where structurally complex habi-

Figure 4. Postswim plasma osmolality $\left(\mathrm{mOsm} \mathrm{kg}^{-1}\right)$ of anadromous (A-Bride, circles) and landlocked (L-Pattagansett, triangles; LRogers, squares) alewives. Measurements were taken after fish swam to exhaustion in freshwater ( $0 \mathrm{ppt})$, seawater (35 and $40 \mathrm{ppt})$, and a $0.5 \mathrm{ppt}$ control. Data are presented as mean plasma osmolality $\pm \mathrm{SE}$ of the mean. Significant main effects of salinity (linear mixed effects model $[\mathrm{LMM}] ; P<0.001$ ) and population (LMM; $P=0.05$ ) were detected but no interaction effect $(P>0.05)$. A color version of this figure is available online. 


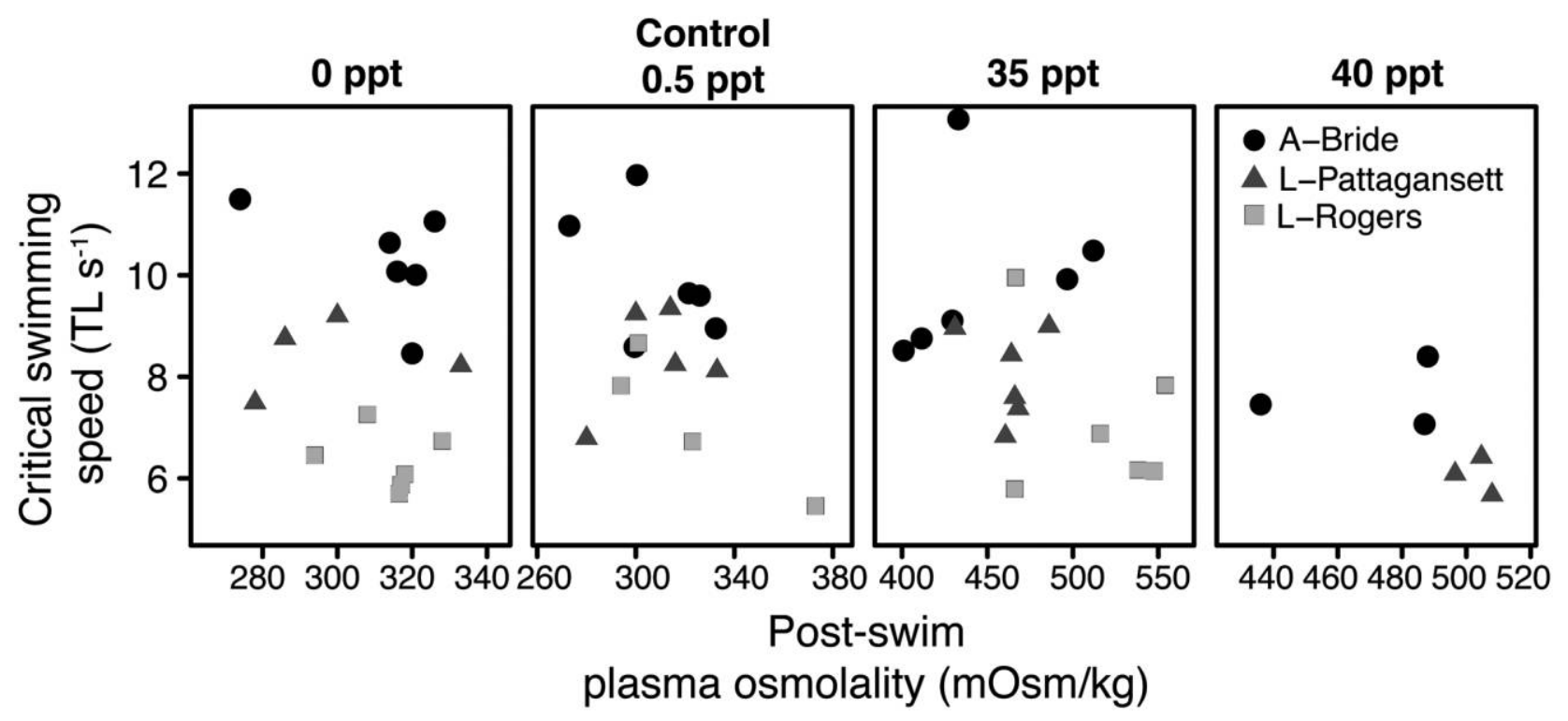

Figure 5. Correlation of critical swimming speed (total body lengths per second [TL s$\left.{ }^{-1}\right]$ ) and postswim plasma osmolality $\left(\mathrm{mOsm} \mathrm{kg}^{-1}\right)$ and among anadromous (A-Bride, circles) and landlocked (L-Pattagansett, triangles; L-Rogers, squares) alewives at 0, 0.5 (control), 35, and 40 ppt treatments. Note differences in scale of $X$-axis. No significant $(P>0.05)$ correlations were found. A color version of this figure is available online.

immediately before collecting blood. Data from Velotta et al (2015) provide the most comparable measures on plasma osmolality of unexercised alewife: juveniles from the same populations examined here were collected at a comparable age and size, reared under identical conditions, and transferred to 0,35 , and 40 ppt. Velotta et al. (2015) found that plasma osmolality varied among populations. Reanalysis of the Velotta et al. (2015) data at $48 \mathrm{~h}$, the time closest to that reported in this study, demonstrates that in seawater, landlocked alewife exhibit approximately $10 \%$ higher plasma osmolality than anadromous alewives (fig. A1). The inconsistency between pre- and postswim plasma osmolality may reflect an osmorespiratory compromise (Nilsson 1986); increased gill perfusion in response to intense exercise comes at the cost of increased passive ion efflux (loss of ions in freshwater, gain of ions in saltwater; Sardella and Brauner 2007), which may have eclipsed population differences in plasma osmolality detected at rest. Indeed, compared with unexercised fish, average postswim plasma osmolality levels were $1.3 \%$ lower in freshwater and $22 \%$ and $18 \%$ higher in 35 and 40 ppt saltwater treatments (fig. 4 compared with fig. A1). We note that because of our swimming trial design, the time at which blood sampling occurred varied among individuals and groups.

While direct transfer to seawater did not affect $U_{\text {crit }}$, salinity in excess of typical seawater negatively influenced swimming performance. A salinity of $40 \mathrm{ppt}$ reduced $U_{\text {crit }}$ by the same magnitude among anadromous and landlocked individuals (fig. 2). This salinity is higher than what alewives would encounter in the wild, and direct transfers to $40 \mathrm{ppt}$ incur population-dependent mortality (Velotta et al. 2015). Transfer to a different salinity (from freshwater to seawater or vice versa) has been shown to reduce $U_{\text {crit }}$ in several species of fish (Brauner et al. 1994; Kolok and Sharkey 1997; Swanson 1998; Plaut 2000). Brauner et al. (1994) suggested that reductions in $U_{\text {crit }}$ following seawater transfer could be caused by plasma ion imbalances that lower the efficiency of muscle contractions. Although we did not observe a significant negative correlation between plasma osmolality and $U_{\text {crit }}$ the small number of measurements at $40 \mathrm{ppt}$ (fig. 5) suggests that pronounced osmotic imbalance might alter prolonged swimming performance in alewife.

The parallel reduction in prolonged swimming performance among independently landlocked alewife populations suggests the influence of common evolutionary processes resulting from the repeated loss of long-distance migration. Selection for higher prolonged swimming performance is expected to be strong in longdistance migrators and to be weak in fishes confined to lentic habitats. Indeed, populations of nonmigratory species often exhibit a reduced $U_{\text {crit }}$ compared with ancestrally anadromous or highly migratory populations (Taylor and McPhail 1986; Taylor and Foote 1991; Tudorache et al. 2007; Dalziel et al. 2012b; Reyes and Baker 2016). Likewise, in migratory sockeye salmon (Oncorhynchus nerka), critical swimming speed is positively correlated with the distance to upstream spawning grounds (Lee et al. 2003), suggesting local adaptation of swimming performance as a function of migratory tendency.

Decreased prolonged swimming performance in nonmigratory populations could have evolved because the capacity for high performance has direct or indirect costs, or it may have evolved by neutral processes (Lahti et al. 2009). A good candidate for a direct cost of maintaining the capacity for high performance is the requirement for high metabolic rates and aerobic scope, physiological characters that have strong fitness effects in the wild (Irschick et al. 2008). Indeed, maximum and routine metabolic rates as well as aerobic scope increase with prolonged swimming performance (Brett 1964; Plaut 2000, 2001; Reidy et al. 2000; 
Marras et al. 2013). In populations of migratory threespine stickleback, higher $U_{\text {crit }}$ is associated with higher maximum (Dalziel et al. $2012 b$ ) and routine (Tudorache et al. 2007) metabolic rates, relative to populations that do not migrate. Among populations of salmon, aerobic scope varies positively with migratory difficulty (e.g., river distance, elevation, and duration), a difference that appears to be attributable to increased maximum metabolic rate (Lee et al. 2003; Eliason et al. 2011, 2013). Together, these studies suggest that maintaining the capacity for high prolonged swimming performance is costly and subject to direct selection.

A related direct cost explanation is that loss of prolonged swimming capacity has occurred as landlocked alewife have adapted to habitat with reduced energy availability. Compared with coastal seawater environments, freshwater habitats are generally lower in food availability (Morgan and Iwama 1991; Kitano et al. 2010; Metcalfe et al. 2016). Landlocked alewife may have evolved reduced rates of energy consumption and storage as a result. In fact, landlocked alewife exhibit relatively slow growth in the wild (Graham 1956; Scott and Crossman 1973) and when reared in seawater in the laboratory (J. P. Velotta, unpublished data). Further work is needed to determine whether the differences in growth rate are accompanied by differences in energetic condition, which could have a bearing on muscle metabolic capacity and thus $U_{\text {crit }}$ (Sullivan and Somero 1983; Martínez et al. 2003). Whether the divergence in prolonged swimming performance is better attributed to selection on energy demand (loss of migration) or supply (reduced feeding and lower condition) will require comparisons across a wider range of landlocked alewife populations from environments varying in productivity.

Further work on the energetics of alewife will be needed to confirm that prolonged swimming performance has decreased in landlocked forms under direct selection. We predict that routine metabolic rate, maximum metabolic rate, and thus aerobic scope will be lower in landlocked forms. Metabolic rate differences may be evident in anatomical differences indicative of oxygen transport and consumption (Claireaux et al. 2005; Eliason et al. 2011; Dalziel et al. 2012a). For example, enhanced aerobic scope associated with migration distance in sockeye salmon appears to be driven by an enhanced cardiac output, which is mediated by enlarged ventricles and better coronary supply (Eliason et al. 2011, 2013; Eliason and Farrell 2016). Relative to benthic lake whitefish (Coregonus clupeaformis), the highly aerobic dwarf ecotype has evolved larger ventricles and higher densities of oxidative muscle fibers and muscle mitochondria, which promote high swimming capabilities (Dalziel et al. 2015). Metabolically active species often have an enhanced capacity for oxygen transport (Suarez 1996), which should be costly to maintain (Dalziel et al. 2012a). Reduced prolonged swimming performance among landlocked alewives is therefore likely to be mediated by physiological changes that influence muscle oxygen supply.

Prolonged swimming capacity has not evolved in alewives by indirect selection arising from a trade-off with growth rate that has been observed in other species. Juvenile growth rate can be negatively correlated with $U_{\text {crit }}$ (Kolok and Oris 1995; Farrell et al. 1997; Billerbeck et al. 2001; Álvarez and Metcalfe 2005; Lee et al. 2010), apparently because rapid growth limits the fraction of aerobic scope available for activity (Arnott et al. 2006). In this scenario, selection for rapid growth in landlocked alewife would cause a reduction in prolonged swimming capacity. As noted above, growth rates are reduced in landlocked alewife, and this scenario is not tenable.

Comparison of burst swimming performance in the anadromous and landlocked life-history forms is also needed. A tradeoff between prolonged and burst swimming performance has been widely demonstrated (Taylor and McPhail 1986; Langerhans 2009; Oufiero et al. 2011; Gerry et al. 2012). Prolonged and burst swimming performance tend to covary negatively because morphological features act antagonistically: fusiform body shapes that minimize drag and enhance steady swimming are not optimized for stability, which is needed during rapid bursts of activity (Langerhans and Reznick 2010). We do not expect that life-history forms of alewife have differentiated along this trade-off, because the relatively fusiform body shape of landlocked alewife is indicative of relatively poor burst swimming performance.

Our results suggest that reductions in swimming performance are uncoupled from evolutionary changes in osmoregulatory abilities and body shape, most likely because these components of performance are responding to different selection pressures or environmental conditions. This finding was unexpected, given that both body shape (e.g., Langerhans and Reznick 2010) and osmoregulatory abilities (e.g., Brauner et al. 1994; Brennan et al. 2016) exert a strong influence on fish swimming. The extent to which selection or neutral processes may account for differences in $U_{\text {crit }}$ cannot be explicitly deduced, although our results suggest that trade-offs with growth rate, burst swimming performance, or both are unlikely. We conclude that loss of long-distance anadromous migrations best explains the reduction of $U_{\text {crit }}$ in landlocked alewife and that this reduction may be mediated by changes in metabolic rate and the transport and delivery of oxygen to swimming muscles. Future work will characterize metabolic and cardiorespiratory capacity differences between alewife populations in order to assess the degree to which the evolution of aerobic performance influences the loss of swimming performance. Nevertheless, the results of this study strongly suggest that relaxation of selection pressures associated with migration is a stronger force in shaping prolonged swimming performance than osmoregulatory abilities or morphological change.

\section{Acknowledgments}

We thank Rebecca Colby, Jeffrey Divino, Meghan Nichols, Diogo Martins, Michael F. O’Dea (1962-2014), Jessie Rack, Amy Regish, Hayley Sullivan, and Andrew Weinstock for assistance with field and laboratory work and Carl Schlichting and Mark Urban for providing insightful comments on early versions of the manuscript. Brigette Zacharczenko provided the line drawing in figure 1. Funding was provided by the University of Connecticut's Department of Ecology and Evolutionary Biology and El Muy Viejo. Any use of trade, product, or firm names is for descriptive purposes only and does not imply endorsement by the US Government. 


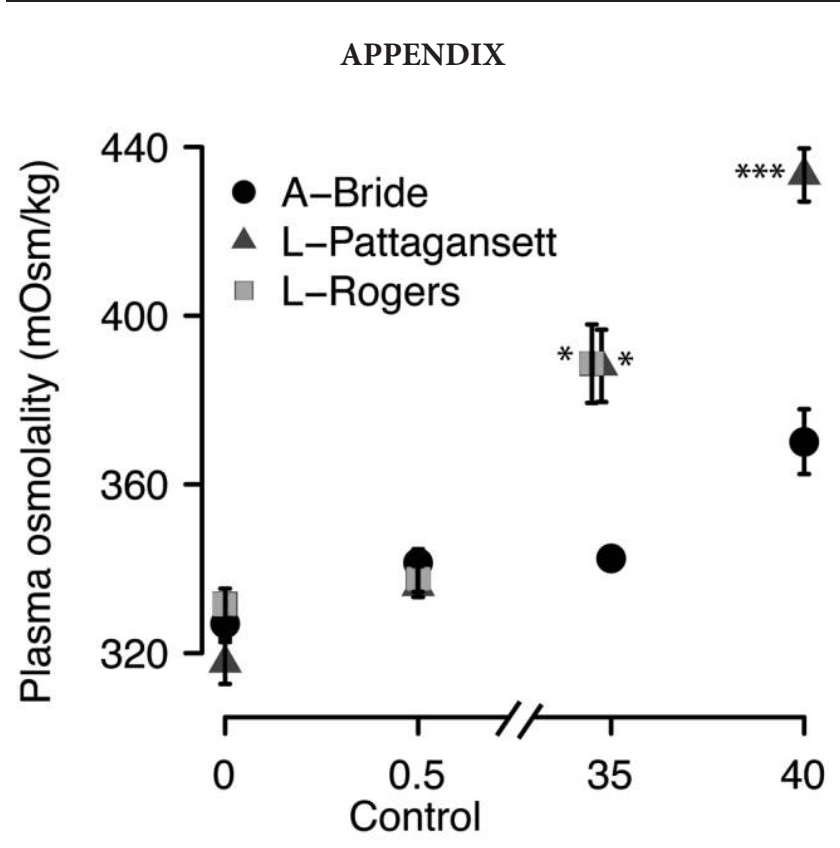

Salinity (ppt)

Figure A1. Plasma osmolality (mOsm $\mathrm{kg}^{-1}$ ) of unexercised anadromous (A-Bride, circles) and landlocked (L-Pattagansett, triangles; L-Rogers, squares) alewives, as reported by Velotta et al. (2015). Values represent mean plasma osmolality \pm SE of the mean. Osmolality was measured on alewives before (control, $0.5 \mathrm{ppt}$ ) and $48 \mathrm{~h}$ after direct transfer to $0 \mathrm{ppt}$ freshwater and 35 and 40 ppt seawater $(n=12$ per population per salinity). A significant population $\times$ salinity interaction was detected (linear mixed effects model; $P=0.002$ ). Figure redrawn from Velotta et al. (2015). A color version of this figure is available online.

\section{Literature Cited}

Adams D.C., F.J. Rohlf, and D.E. Slice. 2004. Geometric morphometrics: ten years of progress following the "revolution." Ital I Zool 71:5-16.

Álvarez D. and N.B. Metcalfe. 2005. Catch-up growth and swimming performance in threespine sticklebacks (Gasterosteus aculeatus): seasonal changes in the cost of compensation. Can I Fish Aquat Sci 62:2169-2176.

Arnold S.J. 1983. Morphology, performance and fitness. Am Zool 23:347-361.

Arnott S.A., S. Chiba, and D.O. Conover. 2006. Evolution of intrinsic growth rate: metabolic costs drive trade-offs between growth and swimming performance in Menidia menidia. Evolution 60:1269-1278.

Beamish F.W.H. 1978. Swimming capacity. Pp. 101-187 in W.S. Hoar and D.J. Randall, eds. Fish physiology. Academic Press, New York.

Bennett A.F. and R.B. Huey. 1990. Studying the evolution of physiological performance. Pp. 251-284 in D. Futuyma and J. Antonovics, eds. Handbook of physiology. Oxford University Press, Oxford.
Berdan E.L. and R.C. Fuller. 2012. Interspecific divergence of ionoregulatory physiology in killifish: insight into adaptation and speciation. LZool 287:283-291.

Billerbeck J.M., T.E. Lankford, and D.O. Conover. 2001. Evolution of intrinsic growth and energy acquisition rates. I. Trade-offs with swimming performance in Menidia menidia. Evolution 55:1863-1872.

Bindon S.D., J.C. Fenwick, and S.F. Perry. 1994. Branchial chloride cell proliferation in the rainbow trout, Oncorhynchus mykiss: implications for gas transfer. Can I Zool 72:13951402.

Brauner C.J., G.K. Iwama, and D.J. Randall. 1994. The effect of short-duration seawater exposure on the swimming performance of wild and hatchery-reared juvenile coho salmon (Oncorhynchus kisutch) during smoltification. Can I Fish Aquat Sci 51:2188-2194.

Brennan R.S., F. Galvez, and A. Whitehead. 2015. Reciprocal osmotic challenges reveal mechanisms of divergence in phenotypic plasticity in the killifish Fundulus heteroclitus. IExp Biol 218:1212-1222.

Brennan R.S., R. Hwang, M. Tse, N.A. Fangue, and A. Whitehead. 2016. Local adaptation to osmotic environment in killifish, Fundulus heteroclitus, is supported by divergence in swimming performance but not by differences in excess postexercise oxygen consumption or aerobic scope. Comp Biochem Physiol A 196:11-19.

Brett J.R. 1964. The respiratory metabolism and swimming performance of young sockeye salmon. LFish Res Board Can 21:1183-1226.

Carneiro P.C.F. and E.C. Urbinati. 2001. Salt as a stress response mitigator of matrinxã, Brycon cephalus (Günther), during transport. Aquac Res 32:297-304.

Claireaux G., D.J. McKenzie, A.G. Genge, A. Chatelier, J. Aubin, and A.P. Farrell. 2005. Linking swimming performance, cardiac pumping ability and cardiac anatomy in rainbow trout. LExp Biol 208:1775-1784.

Dalziel A.C., N. Martin, M. Laporte, H. Guderley, and L. Bernatchez. 2015. Adaptation and acclimation of aerobic exercise physiology in Lake Whitefish ecotypes (Coregonus clupeaformis). Evolution 69:2167-2186.

Dalziel A.C., M. Ou, and P.M. Schulte. 2012a. Mechanisms underlying parallel reductions in aerobic capacity in nonmigratory threespine stickleback (Gasterosteus aculeatus) populations. LExp Biol 215:746-759.

Dalziel A.C., T.H. Vines, and P.M. Schulte. 2012b. Reductions in prolonged swimming capacity following freshwater colonization in multiple threespine stickleback populations. Evolution 66:1226-1239.

Divino J.N., M.Y. Monette, S.D. McCormick, P.H. Yancey, K.G. Flannery, M.A. Bell, J.L. Rollins, et al. 2016. Osmoregulatory physiology and rapid evolution of salinity tolerance in threespine stickleback recently introduced to fresh water. Evol Ecol Res 17:179-201.

Domenici P., H. Turesson, J. Brodersen, and C. Brönmark. 2008. Predator-induced morphology enhances escape locomotion in crucian carp. Proc R Soc B 275:195-201. 
Eliason E.J., T.D. Clark, M.J. Hague, L.M. Hanson, Z.S. Gallagher, K.M. Jeffries, M.K. Gale, et al. 2011. Differences in thermal tolerance among sockeye salmon populations. Science 332:109-112.

Eliason E.J. and A.P. Farrell. 2016. Oxygen uptake in Pacific salmon Oncorhynchus spp.: when ecology and physiology meet. LFish Biol 88:359-388.

Eliason E.J., S.M. Wilson, A.P. Farrell, S.J. Cooke, and S.G. Hinch. 2013. Low cardiac and aerobic scope in a coastal population of sockeye salmon Oncorhynchus nerka with a short upriver migration. LFish Biol 82:2104-2112.

Ellerby D.J. and S.P. Gerry. 2011. Sympatric divergence and performance trade-offs of bluegill ecomorphs. Evol Biol 38: 422-433.

Farrell A.P. 2007. Cardiorespiratory performance during prolonged swimming tests with salmonids: a perspective on temperature effects and potential analytical pitfalls. Philos Trans R Soc B 362:2017-2030.

Farrell A.P., W. Bennett, and R.H. Devlin. 1997. Growthenhanced transgenic salmon can be inferior swimmers. Can L Zool 75:335-337.

Fay C.W., R.J. Neves, and G.B. Pardue. 1982. Species profiles: life histories and environmental requirements of coastal fishes and invertebrates (Mid-Atlantic). Alewife/blueback herring. Fish and Wildlife Service, US Department of the Interior, Washington, DC.

Fish F.E. 1996. Transitions from drag-based to lift-based propulsion in mammalian swimming. Integr Comp Biol 36:628641.

Garland T., Jr., M.D. Cadney, and R.A. Waterland. 2017. Earlylife effects on adult physical activity: concepts, relevance, and experimental approaches. Phvsiol Biochem Zool 90:1-14.

Garland T., Jr., and J.B. Losos. 1994. Ecological morphology of locomotor performance in squamate reptiles. Pp. 240-302 in P.C. Wainwright and S.M. Reilly, eds. Ecological morphology: integrative organismal biology. University of Chicago Press, Chicago.

Gerry S.P., A. Robbins, and D.J. Ellerby. 2012. Variation in faststart performance within a population of polyphenic bluegill (Lepomis macrochirus). Physiol Biochem Zool 85:694-703.

Graham J. 1956. Observations on the alewife, Pomolobus pseudoharengus (Wilson), in fresh water. University of Toronto Press, Toronto.

Hoar W.S. and D.J. Randall. 1978. Terminology to describe swimming activity in fish. Pp. 13-14 in W.S. Hoar and D.J. Randall, eds. Fish physiology. Academic Press, London.

Irschick D.J. 2003. Measuring performance in nature: implications for studies of fitness within populations. Integr Comp Biol 43:396-407.

Irschick D.J. and T. Garland. 2001. Integrating function and ecology in studies of adaptation: investigations of locomotor capacity as a model system. Annu Rev Ecol Syst 32:367-396.

Irschick D.J., J.J. Meyers, J.F. Husak, and J.-F.L. Galliard. 2008. How does selection operate on whole-organism functional performance capacities? a review and synthesis. Evol Ecol Res 10:177-197.
Jain K.E., I.K. Birtwell, and A.P. Farrell. 1998. Repeat swimming performance of mature sockeye salmon following a brief recovery period: a proposed measure of fish health and water quality. Can I Zool 76:1488-1496.

Johnson D.L. and M.T. Metcalf. 1982. Causes and controls of freshwater drum mortality during transportation. Trans Am Fish Soc 111:58-62.

Jones A.W., E.P. Palkovacs, and D.M. Post. 2013. Recent parallel divergence in body shape and diet source of alewife life history forms. Evol Ecol 27:1175-1187.

Kitano J., S.C. Lema, J.A. Luckenbach, S. Mori, Y. Kawagishi, M. Kusakabe, P. Swanson, et al. 2010. Adaptive divergence in the thyroid hormone signaling pathway in the stickleback radiation. Curr Biol 20:2124-2130.

Klingenberg C.P. 2011. MorphoJ: an integrated software package for geometric morphometrics. Mol Ecol Resour 11:353-357.

Kolok A.S. 1999. Interindividual variation in the prolonged locomotor performance of ectothermic vertebrates: a comparison of fish and herpetofaunal methodologies and a brief review of the recent fish literature. Can I Fish Aquat Sci 56: 700-710.

Kolok A.S. and J.T. Oris. 1995. The relationship between specific growth rate and swimming performance in male fathead minnows (Pimephales promelas). Can I Zool 73:2165-2167.

Kolok A.S. and D. Sharkey. 1997. Effect of freshwater acclimation on the swimming performance and plasma osmolarity of the euryhaline gulf killifish. Trans Am Fish Soc 126:866-870.

Kozak G.M., R.S. Brennan, E.L. Berdan, R.C. Fuller, and A. Whitehead. 2014. Functional and population genomic divergence within and between two species of killifish adapted to different osmotic niches. Evolution 68:63-80.

Lahti D.C., N.A. Johnson, B.C. Ajie, S.P. Otto, A.P. Hendry, D.T. Blumstein, R.G. Coss, et al. 2009. Relaxed selection in the wild. Trends Ecol Evol 24:487-496.

Lailvaux S.P. and D.J. Irschick. 2006. A functional perspective on sexual selection: insights and future prospects. Anim Behav 72:263-273.

Langerhans R.B. 2009. Trade-off between steady and unsteady swimming underlies predator-driven divergence in Gambusia affinis. LEvol Biol 22:1057-1075.

Langerhans R.B., L.J. Chapman, and T.J. Dewitt. 2007. Complex phenotype-environment associations revealed in an East African cyprinid. LEvol Biol 20:1171-1181.

Langerhans R.B. and D.N. Reznick. 2010. Ecology and evolution of swimming performance in fishes: predicting evolution with biomechanics. Pp. 200-248 in B.G. Kapoor and P. Domenici, eds. Fish locomotion: an eco-ethological perspective. Science, Oxford.

Lee C.G., A.P. Farrell, A. Lotto, M.J. MacNutt, S.G. Hinch, and M.C. Healey. 2003. The effect of temperature on swimming performance and oxygen consumption in adult sockeye (Oncorhynchus nerka) and coho (O. kisutch) salmon stocks. LExp Biol 206:3239-3251.

Lee W.-S., P. Monaghan, and N.B. Metcalfe. 2010. The trade-off between growth rate and locomotor performance varies with perceived time until breeding. LExp Biol 213:3289-3298. 
Marras S., S.S. Killen, P. Domenici, G. Claireaux, and D.J. McKenzie. 2013. Relationships among traits of aerobic and anaerobic swimming performance in individual European sea bass Dicentrarchus labrax. PLOS One 8:e72815.

Martínez M., H. Guderley, J.-D. Dutil, P.D. Winger, P. He, and S.J. Walsh. 2003. Condition, prolonged swimming performance and muscle metabolic capacities of cod Gadus morhua. LExp Biol 206:503-511.

McCormick S.D. 2013. Smolt physiology and endocrinology. Pp. 199-251 in S.D. McCormick, A.P. Farrell, and C.J. Brauner, eds. Fish physiology. Vol. 32. Euryhaline fishes. Elsevier, New York.

McKenzie D.J., E. Cataldi, P. Romano, E.W. Taylor, S. Cataudella, and P. Bronzi. 2001. Effects of acclimation to brackish water on tolerance of salinity challenge by young-of-theyear Adriatic sturgeon (Acipenser naccarii). Can I Fish Aquat Sci 58:1113-1121.

Metcalfe N.B., T.E. Van Leeuwen, and S.S. Killen. 2016. Does individual variation in metabolic phenotype predict fish behaviour and performance? LFish Biol 88:298-321.

Morgan J.D. and G.K. Iwama. 1991. Effects of salinity on growth, metabolism, and ion regulation in juvenile rainbow and steelhead trout (Oncorhynchus mykiss) and fall chinook salmon (Oncorhynchus tshawytscha). Can I Fish Aquat Sci 48:2083-2094.

Nikinmaa M., A. Soivio, T. Nakari, and S. Lindgren. 1983. Hauling stress in brown trout (Salmo trutta): physiological responses to transport in fresh water or salt water, and recovery in natural brackish water. Aquaculture 34:93-99.

Nilsson S. 1986. Control of gill blood flow. Pp. 86-101 in S. Nilsson and S. Holmgren, eds. Fish physiology: recent advances. Springer, Dordrecht.

Norin T. and T.D. Clark. 2016. Measurement and relevance of maximum metabolic rate in fishes. L Fish Biol 88:122151.

Oufiero C.E., M.R. Walsh, D.N. Reznick, and T. Garland Jr. 2011. Swimming performance trade-offs across a gradient in comunity composition in Trinidadian killifish (Rivulus hartii). Ecology 92:170-179.

Palkovacs E.P., K.B. Dion, D.M. Post, and A. Caccone. 2008. Independent evolutionary origins of landlocked alewife populations and rapid parallel evolution of phenotypic traits. $\underline{\mathrm{Mol}}$ Ecol 17:582-597.

Plaut I. 2000. Resting metabolic rate, critical swimming speed, and routine activity of the euryhaline cyprinodontid, Aphanius dispar, acclimated to a wide range of salinities. Physiol Biochem Zool 73:590-596.

2001. Critical swimming speed: its ecological relevance. Comp Biochem Physiol A Mol Integr Physiol 131:41-50.

Reidy S.P., S.R. Kerr, and J.A. Nelson. 2000. Aerobic and anaerobic swimming performance of individual Atlantic cod. LExp Biol 203:347-357.

Reyes M.L. and J.A. Baker. 2016. Prolonged swimming performance within the threespine stickleback (Gasterosteus aculeatus) adaptive radiation and the effect of dietary restriction. Evol Ecol Res 17.
Rohlf F.J. 2010. TPSDig2. 2.16. Department of Ecology and Evolutionary Biology, SUNY, Stony Brook.

Rohlf F.J. and D. Slice. 1990. Extensions of the procrustes method for the optimal superimposition of landmarks. Syst Biol 39:40-59.

Sardella B.A. and C.J. Brauner. 2007. The osmo-respiratory compromise in fish: The effects of physiological state and the environment. P. in M.N. Fernandes, F.T. Rantin, M.L. Glass, and B.G. Kapoor eds. Fish Respir Environ. Science Publishers, Enfield, $\mathrm{NH}$.

Schneider C.A., W.S. Rasband, and K.W. Eliceiri. 2012. NIH Image to ImageJ: 25 years of image analysis. Nat Methods 9: 671-675.

Schultz E.T. and S.D. McCormick. 2013. Euryhalinity in an evolutionary context. Pp. 477-533 in S.D. McCormick, A.P. Farrell, and C.J. Brauner eds. Euryhaline Fishes, Fish Physiology. Elsevier, New York.

Scott G.R. and P.M. Schulte. 2005. Intraspecific variation in gene expression after seawater transfer in gills of the euryhaline killifish Fundulus heteroclitus. Comp Biochem Phvsiol A Mol Integr Physiol 141:176-182.

Scott W. and E. Crossman. 1973. Freshwater fishes of Canada. Fish Res Board Can Bull 184.

Stanley J.G. and P.J. Colby. 1971. Effects of temperature on electrolyte balance and osmoregulation in the alewife (Alosa pseudoharengus) in fresh and sea water. Trans Am Fish Soc 100:624-638.

Staurnes M., T. Sigholt, G. Lysfjord, and O.A. Gulseth. 1992. Difference in the seawater tolerance of anadromous and landlocked populations of arctic char (Salvelinus alpinus). Can I Fish Aquat Sci 49:443-447.

Suarez R.K. 1996. Upper limits to mass-specific metabolic rates. Annu Rev Physiol 58:583-605.

Sullivan K.M. and G.N. Somero. 1983. Size- and diet-related variations in enzymic activity and tissue composition in the sablefish, Anoplopoma fimbria. Biol Bull 164:315-326.

Swanson C. 1998. Interactive effects of salinity on metabolic rate, activity, growth and osmoregulation in the euryhaline milkfish (Chanos chanos). L Exp Biol 201:3355-3366.

Taylor E.B. and C.J. Foote. 1991. Critical swimming velocities of juvenile sockeye salmon and kokanee, the anadromous and non-anadromous forms of Oncorhynchus nerka (Walbaum). L Fish Biol 38:407-419.

Taylor E.B. and J.D. McPhail. 1986. Prolonged and burst swimming in anadromous and freshwater threespine stickleback, Gasterosteus aculeatus. Can I Zool 64:416-420.

Tseng Y.-C. and P.-P. Hwang. 2008. Some insights into energy metabolism for osmoregulation in fish. Comp Biochem Physiol Part C Toxicol Pharmacol, "Diversity in a Changing Environment" - the International Conference of Comparative Physiology, Biochemistry and Toxicology and 6th Chinese Comparative Physiology Conference, 2007 148:419-429.

Tudorache C., R. Blust, and G. De Boeck. 2007. Swimming capacity and energetics of migrating and non-migrating morphs of three-spined stickleback Gasterosteus aculeatus L. and their ecological implications. LFish Biol 71:1448-1456. 
Velotta J.P., S.D. McCormick, R.J. O'Neill, and E.T. Schultz. 2014. Relaxed selection causes microevolution of seawater osmoregulation and gene expression in landlocked alewives. Oecologia 175:1081-1092.

Velotta J.P., S.D. McCormick, and E.T. Schultz. 2015. Tradeoffs in osmoregulation and parallel shifts in molecular function follow ecological transitions to freshwater in the Alewife. Evolution 69:2676-2688.

Wagner G.N., L.J. Kuchel, A. Lotto, D.A. Patterson, J.M. Shrimpton, S.G. Hinch, and A.P. Farrell. 2006. Routine and active metabolic rates of migrating adult wild sockeye salmon (Oncorhynchus nerka Walbaum) in seawater and freshwater. Physiol Biochem Zool 79:100-108.

Walker J.A. 1997. Ecological morphology of lacustrine threespine stickleback Gasterosteus aculeatus L. (Gasterosteidae) body shape. Biol I Linn Soc 61:3-50.

Webb P.W. 1975. Hydrodynamics and energetics of fish propulsion. Bull Fish Res Board Can.

- 1982. Locomotor patterns in the evolution of actinopterygian fishes. Am Zool 22:329-342.
1984. Body form, locomotion and foraging in aquatic vertebrates. Integr Comp Biol 24:107-120.

Whitehead A. 2010. The evolutionary radiation of diverse osmotolerant physiologies in Killifish (Fundulus sp.). Evolution 64:2070-2085.

Whitehead A. and D.L. Crawford. 2006. Neutral and adaptive variation in gene expression. Proc Natl Acad Sci 103:54255430.

Whitehead A., J.L. Roach, S. Zhang, and F. Galvez. 2011. Genomic mechanisms of evolved physiological plasticity in killifish distributed along an environmental salinity gradient. Proc Natl Acad Sci 108:6193-6198.

2012. Salinity- and population-dependent genome regulatory response during osmotic acclimation in the killifish (Fundulus heteroclitus) gill. LExp Biol 215:1293-1305.

Zelditch M.L., D.L. Swiderski, and H.D. Sheets. 2012. Geometric Morphometrics for Biologists: A Primer. Academic Press.

Zydlewski J. and S.D. McCormick. 1997. The loss of hyperosmoregulatory ability in migrating juvenile American shad, Alosa sapidissima. Can J Fish Aquat Sci 54:2377-2387. 